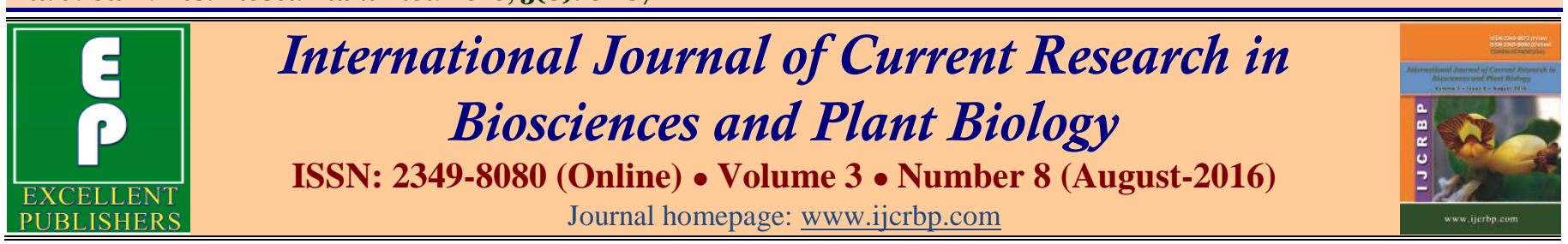

Original Research Article

doi: http://dx.doi.org/10.20546/ijerbp.2016.308.013

\title{
Isolation of Lipid Producing Organisms and Their Properties as Biofuel
}

\author{
Sanskruti Mane and Savanta V. Raut* \\ Department of Microbiology, Bhavan's College, Munshi Nagar, Andheri [W], Mumbai-40 oo58, India \\ *Corresponding author.
}

\begin{abstract}
A bstract
The research project was performed to isolate single cell oil producing organisms and study its application for production of biofuel. Microorganisms were isolated from natural samples like fertile soil, lake water from two different places, mangrove soil, and sewage. The lipid content of cells was predicted using Sudan IV stain. Two isolates were selected for GC-MS for FAME analysis of both samples out of which one of the isolate (PDA 1) showed presence of palmitic acid (C16:0) (2.72\%) in results obtained. In this work, organic (peptone) and inorganic $(\mathrm{NH} 4 \mathrm{Cl})$ nitrogen sources were evaluated along with glucose as carbon source for isolate PDA 1. Isolate PDA 1 was identified to be Enterobacter asburiae. It was observed that complex organic nitrogen source like peptone showed more amount of lipid production. Cetane number was calculated considering palmitic acid composition. By using a more suitable medium for isolation of oleaginous microorganisms more amount of lipid production can be obtained and could have application for production of biofuel if their fatty acid composition shows values significant for use as biofuel.
\end{abstract}

\section{Introduction}

Lipids are produced by all microorganisms usually in the range of 6 to $8 \%$ per dry biomass principally as components for the cell membrane. Yeast strains produce mainly fatty acids which are similar in composition to those in plant oils containing predominantly saturated or monounsaturated fatty acids with carbon lengths of C16 and C18 (Schulze et al., 2014). Lipid accumulation usually occurs in cultures with limited nitrogen and excess carbon. In high $\mathrm{C} / \mathrm{N}$ ratio media, yeasts convert excess carbon into lipid. Environmental conditions, such as temperature and $\mathrm{pH}$, have also been shown to be factors controlling lipid accumulation and composition (Kraisintu et al., 2010).

The $\mathrm{C} / \mathrm{N}$ (carbon to nitrogen) ratio of the respective cultivation media is one of the most important parameters that influence the production of microbial lipids and carotenoids (Braunwald et al., 2013). Biodiesel is a mixture of fatty acids (FAs) methyl esters derived from triacylglycerols (TAGs) and it is regarded as a major resource to face high energy prices and potential depletion of fossil oils reservoirs. During the past decade, heterotrophic oleaginous microorganisms have triggered significant attention and the utilization of this oleaginous biomass has been successfully exploited as a source of TAGs for the production of biodiesel. The biomass of oleaginous microorganisms is an optimal and abundant source of TAGs which exhibit similar FAs composition and energy value to plant oils (Amaretti et al., 2012).

The major fatty acids present in the lipids produced by oleaginous microorganisms are myristic acid (C14:0), palmitic acid (C16:0), stearic acid (C18:0), oleic acid (C18:1), linoleic acid (C18:2), and linolenic acid (C18:3); all of which can be converted to biodiesel through a transesterification reaction (Ruan et al., 2012). 
Cetane number $(\mathrm{CN})$ is widely used as diesel fuel quality parameter related to the ignition delay time and combustion quality. Higher the cetane number is, better it is in its ignition properties (Ramos et al., 2009).

\section{Materials and methods}

\section{Sample collection}

The samples were collected from different places like Lake water from Bhavan's College, Andheri (W), Lake water from Powai, Mumbai, Fertile soil from Botanical garden, Bhavan's College, Andheri (W), Mangrove soil from Bhayander creek and sewage. One gram of soil sample or $1 \mathrm{ml}$ of water / sewage sample was added to $50 \mathrm{ml}$ of enrichment medium and incubated on shaker for 3-4 days.

\section{Isolation of lipid producing organisms}

Lipid producing organisms were isolated using Enrichment technique in which medium consisting of Minimal Medium, $0.15 \mathrm{~g} / 100 \mathrm{ml}$ Yeast extract, $1 \mathrm{ml}$ of $10 \%$ Dextrose was used. $5 \mathrm{~g}$ of sample was added to enrichment medium and Incubated on rotary shaker for 3-4 days at room temperature.

\section{After enrichment the enriched sample were streaked on agar plates containing}

1. Minimal Medium $+0.15 \mathrm{~g} / 100 \mathrm{ml}$ Yeast extract $+1 \mathrm{ml}$ of $10 \%$ Dextrose

\section{Potato Dextrose agar}

Inoculum was prepared by transferring one loop full of 24 hour culture grown on above media to a test tube containing $5 \mathrm{ml}$ of minimal medium $+0.15 \mathrm{~g} / 100 \mathrm{ml}$ Yeast extract $+1 \mathrm{ml}$ of $10 \%$ Dextrose and incubated on shaker at room temperature for 2 days.

\section{Screening for oleaginous microorganisms}

The test tubes which were incubated with 24 hour old culture in $5 \mathrm{ml}$ of medium as mentioned above were added with few drops of Sudan IV stain as indicator of lipid production to determine lipid production qualitatively. Sudan IV stains lipids reddish orange.

Quantitative test was also performed using stock solution of palmitic acid $(100 \mathrm{mg} / \mathrm{ml})$, ethanol was used as diluent, 1 drop of stain was added to $1 \mathrm{ml}$ of total volume.
Inoculum was prepared by transferring one loop full of $24 \mathrm{hrs}$ culture grown to a test tube containing $5 \mathrm{ml}$ of minimal medium, $0.15 \mathrm{~g} / 100 \mathrm{ml}$ Yeast extract, $1 \mathrm{ml}$ of $10 \%$ Dextrose. To extract the lipid produced, $5 \mathrm{ml}$ of Diethyl ether was added to test tube, the layer of Diethyl ether containing lipids was transferred to another tube, Diethyl ether was allowed to evaporate. 1 drop of Sudan IV stain was added. Lipid production was estimated colorimetrically (O.D. at 530nm).

The effect of carbon and nitrogen sources was determined using different concentrations of glucose, $\mathrm{NH}_{4} \mathrm{Cl}$, Peptone in medium $(7 \mathrm{~g} / \mathrm{L}$ KH $2 \mathrm{PO} 4,5 \mathrm{~g} / \mathrm{L}$ $\mathrm{NaH} 2 \mathrm{PO} 4,1.5 \mathrm{~g} / \mathrm{L} \mathrm{MgSO} 4.7 \mathrm{H} 2 \mathrm{O}, 0.08 \mathrm{~g} / \mathrm{L}$ Fecl3.6H20, $0.01 \mathrm{~g} / \mathrm{L} \quad \mathrm{ZnSO} 4.7 \mathrm{H} 2 \mathrm{O}, \quad 0.1 \mathrm{~g} / \mathrm{L} \quad \mathrm{CaCl} 2.2 \mathrm{H} 2 \mathrm{O}, \quad 0.1 \mathrm{~g} / \mathrm{L}$ MnSO4.5H20, 0.1g/L CuSO.5H2O, pH below 4).

\section{Determination of microbial dry biomass}

The selected isolates were grown in medium (Minimal Medium $+0.15 \mathrm{~g} / 100 \mathrm{ml}$ Yeast extract $+1 \mathrm{ml}$ of $10 \%$ Dextrose, $\mathrm{pH}$ adjusted below 4). The biomass was collected by centrifugation and weighed. The biomass was used for extraction of lipids and direct transesterification.

\section{Extraction of lipids}

Extraction of lipids was carried out using modified methodology of Folch et al. (Castanha et al., 2013).

\section{Direct transesterification}

Direct tranesterification process was carried out. Dried yeast biomass was mixed with $20 \mathrm{ml}$ volume of methanol containing concentrated sulfuric acid to final concentration of $0.02 \mathrm{~mol} / \mathrm{L}$. Reaction carried out in glass vials. The glass vials were kept in boiling water bath for 20 mins. To the filtrate hexane was added to recover FAMEs. Upper hexane layer containing FAMEs was collected and analysed by GC-MS.

\section{Analysis of FAME}

The upper hexane layer obtained after direct transesterification was analysed by GC-MS.

Make of MS: Jeol,

Model: Accu TOF,

Specification: EI / CI Source, Time of Flight Analyser, Mass range - 10-2000 amu, Mass resolution- 6000

Make of GC: Agilent, 7890, FID detector, Head Space injector, Combipal autosampler 
GC-MS was performed at IIT Powai, Mumbai, Maharashtra.

\section{Identification of isolate}

Identification of one of the isolate was done by VITEK system at Sunflower Laboratory \& Diagnostic Centre, Malad (W).

\section{Results and discussion}

The samples were obtained from natural sources such as lakes, soil, sewage for isolation of oleaginous microorganisms. In preliminary study 2 isolates from Powai lake water sample, 4 isolates from Bhavan's lake water sample, 2 isolates from sewage sample, 2 isolates from fertile soil sample and 3 isolates from mangrove soil sample (samples that can utilise dextrose/ glucose as carbon source) were isolated.

It had been well studied that lipid production for microorganisms requires a medium that is rich or excesss in sugars or polysaccharides and with little of other nutrients, especially nitrogen. The activity of Nicotinamide Adenine dinucleotide isocitrate dehydrogenase (NAD-IDH) lowers due to low nitrogen in the media, which results in the repression of TCA cycle, wherein protein synthesis is stopped and induces lipid accumulation (Neema and Kumari, 2013).

Lipids are produced by all microorganisms usually in the range of 6 to $8 \%$ per dry biomass principally as components for the cell membrane. The yield and type of lipid is dependent on several factors including the type of microorganism, the culture conditions and the chosen substrates (Schulze et al., 2014). Oleaginous microorganisms including yeasts, bacteria, filamentous fungi and microalgae, convert a carbon source when it is available in excess into intracellular triacylglycerols (TAG) as soon as a nitrogen limitation occurs. These lipids are also called single cell oils (SCO) and are stored as lipid droplets within cells (Schulze et al., 2014). SCOs are lipids produced by oleaginous microorganisms including bacteria, yeast, fungi, and algae that are capable of accumulating at least $20 \%$ of their dry cell mass as lipids (Bonturi et al, 2015).

The isolates were further tested using Sudan IV stain to determine the lipid content qualitatively.

Sudan IV is one of the dyes used for Sudan staining. For staining purposes Sudan IV can be made up in propylene glycol. This is used in the dye saturated in isopropyl alcohol, $95 \%$ ethanol or $0.05 \%$ by weight in acetone:ethanol:water (50:35:15). The idea is to use a moderately apolar solvent to solubilize the dye allowing it to partition into the highly apolar fat without the solvent solubilizing the fat to be stained (Patel et al., 2015).

The Sudan IV stains the lipids to reddish orange colour therefore a positive test shows reddish orange colour. Sudan IV (C24H20N4O) is a lysochrome (fat soluble dye) diazo dye used for the staining of lipids, triglycerides and lipoproteins on frozen paraffin sections. It has the appearance of reddish brown crystals with melting point $199^{\circ} \mathrm{C}$ and maximum absorption at $530(357) \mathrm{nm}$. Sudan IV is one of the dyes used for Sudan staining. Similar dyes include Oil Red O, Sudan III and Sudan Black B. Staining is an important biochemical technique, offering the ability to visually qualify the presence of the fatty compound of interest without isolating it.

An attempt was made to quantitatively determine the lipid content of the isolates selected by plotting palmitic acid standard plot and determining the lipid content in the sample calorimetrically at $530 \mathrm{~nm}$ with the help of change in the intensity of the colour of Sudan IV stain. The tubes were added with 1 drop of stain. The palmitic acid standard plot did not show appropriate results and gradation. Considering the O.D. value of first concentration of lipid $(10 \mathrm{mg} / \mathrm{ml})$ the concentration of lipid present in 5 selected isolates was predicted. They were grown in medium (Minimal medium, $0.15 \mathrm{~g}$ Y.E, $1 \mathrm{ml}$ of $10 \%$ Dextrose). To extract lipid produced the test tubes were added with diethyl ether. The ether layer containing lipids was separated and stained with one drop of Sudan IV stain. The results of Sudan IV staining are shown in Table 1. Two isolates showing positive response to lipid staining were selected and grown in 2 litres of medium to obtain biomass from it.

Table 1. Results of Sudan IV staining.

\begin{tabular}{lllll}
\hline Isolates & $\begin{array}{l}\text { Sudan } \\
\text { staining }\end{array}$ & $\begin{array}{l}\text { O.D at } \\
\text { 530nm }\end{array}$ & $\begin{array}{l}\text { Concentration } \\
\text { of lipid } \\
\text { (mg/5ml) }\end{array}$ & $\begin{array}{l}\text { Concentration } \\
\text { of lipid in }(\mathbf{g})\end{array}$ \\
\hline PDA 1 & Dark & 0.62 & 22.96 & 0.45 \\
PDA 4 & Light & 0.22 & 8.148 & 0.16 \\
M1 & Light & 0.29 & 10.74 & 0.21 \\
M2 & Dark & 1.3 & 48.14 & 0.96 \\
M3 & Light & 0.36 & 13.33 & 0.26 \\
\hline
\end{tabular}

Key: PDA 1- isolate obtained from Fertile soil sample; PDA 4- isolate obtained from Powai lake water sample; M1, M2 and M3-isolates obtained from Mangrove soil sample. 
Table 2. Lipid production from biomass obtained.

\begin{tabular}{lll}
\hline Sample & $\begin{array}{l}\text { Total biomass }(\mathrm{g}) \\
\text { for each isolate }\end{array}$ & $\begin{array}{l}\text { Lipid produced }(\mathrm{g}) \\
\text { approx. values }\end{array}$ \\
\hline PDA 1 & 6.36 & 0.31 \\
PDA 4 & 5.16 & 0.15 \\
\hline
\end{tabular}

Key: PDA 1- isolate obtained from Fertile soil sample;

PDA 4- isolate obtained from Powai lake water sample.

The dry biomass obtained from each isolate after centrifugation at $2000 \mathrm{rpm}$ for $20 \mathrm{~min}$ is tabulated in Table 2. The biomass obtained was used for two purposes: 1) Extraction of lipids and 2) Transesterification. The process of lipid extraction was followed according to modified methodology of Folch and co-workers (Castanha et al., 2013).

Most of the lipid extraction methods generally involve cell breakage and extraction with organic solvents. An efficient extraction requires the solvent to fully penetrate the cell mass and have a polarity similar to that of the target compounds. Yeasts have some characteristics that can make lipid extraction difficult, such as their dense cell wall, which can be recalcitrant to many solvents, especially because neutral lipids are stored intracellularly in lipid bodies. Also, lipid extractability differs according to the species, physical properties of the cell, and lipid composition of the SCO (Bonturi et al., 2015).

Table 3. Effect of carbon and nitrogen sources on lipid production.

\begin{tabular}{llll}
\hline Parameters & $\begin{array}{l}\text { O.D at } \\
\mathbf{5 3 0} \mathbf{~ n m}\end{array}$ & $\begin{array}{l}\text { Conc. of } \\
\text { lipid(mg/5ml) }\end{array}$ & $\begin{array}{l}\text { Conc. of } \\
\text { lipid (g) }\end{array}$ \\
\hline Glu: 40, $\mathrm{NH}_{4} \mathrm{Cl}: 4$ & 0.03 & 1.11 & 0.02 \\
Glu: 40, Pep: 4 & 0.07 & 2.59 & 0.05 \\
Glu: 30, $\mathrm{NH}_{4} \mathrm{Cl}: 3$ & 0.01 & 0.37 & 0.007 \\
Glu: 30, Pep: 3 & 0.02 & 0.74 & 0.01 \\
Glu: 20, $\mathrm{NH}_{4} \mathrm{Cl}: 2$ & 0.06 & 2.22 & 0.04 \\
Glu: 20, Pep: 2 & 0.03 & 1.11 & 0.02 \\
\hline
\end{tabular}

Lipid accumulation usually occurs in cultures with limited nitrogen and excess carbon. In high $\mathrm{C} / \mathrm{N}$ ratio media, yeasts convert excess carbon into lipid. Environmental conditions, such as temperature and $\mathrm{pH}$, have also been shown to be factors controlling lipid accumulation and composition (Kraisintu et al., 2010).

The $\mathrm{C} / \mathrm{N}$ (carbon to nitrogen) ratio of the respective cultivation media is one of the most important parameters that influence the production of microbial lipids and carotenoids (Braunwald et al., 2013).

The optimisation of medium was performed using different concentrations of carbon and nitrogen sources and following the Sudan IV staining procedure as mentioned previously and from values of O.D. at $530 \mathrm{~nm}$ the concentration of lipid was determined. The results of optimisation study are listed in table 3 . In this work organic (peptone) and inorganic $\left(\mathrm{NH}_{4} \mathrm{Cl}\right)$ nitrogen sources were evaluated along with glucose as carbon source. It was observed that complex organic nitrogen source like peptone showed more amount of lipid production (Table 3). It was observed that addition of peptone as nitrogen source resulted in obtaining more amount of lipid. Optimisation by Plackett- Burman Design suggested $\mathrm{NH} 4 \mathrm{Cl}$ as significant variable for lipid production (Table 4).

Nitrogen plays a very important role as the accumulation of lipids starts after depletion of nitrogen from the cultivation broth. In addition, the form of nitrogen (organic or inorganic) highly affects the production of lipids. For these reasons it is of great importance to evaluate the nitrogen source as well as the ratio of the carbon to nitrogen concentrations $(\mathrm{C}: \mathrm{N})$.Complex organic nitrogen sources (yeast extract and peptone) were more favourable for production of lipids (Matsakas et al., 2014).

Table 4. Statistical analysis by Plackett-Burman method.

\begin{tabular}{llll}
\hline & $\begin{array}{l}\text { A } \\
\text { (Glucose) }\end{array}$ & $\begin{array}{l}\text { B } \\
\left(\mathbf{N H}_{4} \mathbf{C l}\right)\end{array}$ & $\begin{array}{l}\text { C } \\
\text { (Peptone) }\end{array}$ \\
\hline$\sum(\mathrm{H})$ & 0.03 & 0.07 & 0.057 \\
$\sum(\mathrm{L})$ & 0.043 & 0.017 & 0.03 \\
Difference & 0.013 & 0.053 & 0.027 \\
Mean square & 0.00004 & 0.0007 & 0.00018 \\
\hline
\end{tabular}

\section{Prediction of biodiesel properties}

Cetane number was predicted using Equation 1 (Bonturi et al., 2015):

CNME $=58.1+2.8[(\mathrm{nc}-8 \div 2)] \times \mathrm{nD}$ (1)

Where, $\mathrm{nc}$ is the number of carbon atoms and $\mathrm{nDB}$ is the number of double bonds of the fatty acid.

The cold filter plugging point (CFPP) was calculated as a function of the long chain saturated factor (LCSF), with Equations (2) and (3) (Bonturi et al., 2015):

LCSF $=0.1 \times C 16(w t \%)+0.5 \times C 18(w t \%)+1 \times C 20(w t \%)+1.5 \times C 22(w t \%)+2 \times(w t \%) \ldots . .(2)$

Where, wt $\%$ corresponds to the amount of methyl ester (in percentage).

CFPP $=3.1417 \times$ LCSF -16.477 (3) 
Cetane number of biodiesel (Saravanan and Chandrashekhar, 2013):

Cetane number $=$

$\left(61.03+0^{*} X 1+0.1025^{*} X 2+0.133^{*} X 3+0.152^{*} X 4-0.001^{*} X 5-0.037^{*} X 6-0.243^{*} X 7-0.395^{*} X 8\right)$

Where, $\mathrm{X} 1 \ldots . . \mathrm{X} 8$ are $\%$ of fatty acid composition.

Calculation of percentage of each compound in sample

Percent $A=$ Area of $A \div$ Total area $\times 100$

Table 5. Prediction of biodiesel properties of lipid produced by selected isolate.

\begin{tabular}{llllll}
\hline Isolate & $\begin{array}{l}\text { \% wt. of } \\
\text { C16: 0 }\end{array}$ & CN $_{\text {ME }}$ & $\begin{array}{l}\text { Cetane } \\
\text { number }\end{array}$ & LCSF & CFPP \\
\hline PDA 1 & Approx. & Approx. & $\begin{array}{l}\text { Approx. } \\
\text { Approx. }\end{array}$ & Approx. \\
& 2.72 & 58.1 & 61.391 & 1.272 & -12.48 \\
\hline
\end{tabular}

Biodiesel is a mixture of fatty acids (FAs) methyl esters derived from triacylglycerols (TAGs) and it is regarded as a major resource to face high energy prices and potential depletion of fossil oils reservoirs. During the past decade, heterotrophic oleaginous microorganisms have triggered significant attention and the utilization of this oleaginous biomass has been successfully exploited as a source of TAGs for the production of biodiesel. The biomass of oleaginous microorganisms is an optimal and abundant source of TAGs which exhibit similar FAs composition and energy value to plant oils (Amaretti et al., 2012).

The direct transesterification reaction was carried according to Gohel et al. (2013). The upper hexane layer obtained after direct transesterification was analysed by GC-MS. Isolate PDA 1 showed presence of Hexadecanoic acid (Palmitic acid) in analysis. Table 6 and 7 lists the components and other details of components identified in GC-MS analysis. The major fatty acids present in the lipids produced by oleaginous microorganisms are myristic acid (C14:0), palmitic acid (C16:0), stearic acid (C18:0), oleic acid (C18:1), linoleic acid (C18:2), and linolenic acid (C18:3); all of which can be converted to biodiesel through a transesterification reaction (Ruan et al., 2012). The properties of the triglyceride and the biodiesel fuel are determined by the amounts of each fatty acid that are present in the molecules. Chain length and number of double bonds determine the physical characteristics of both fatty acids and triglycerides (Ramos et al., 2009).

Table 6. GC-MS analysis of isolate PDA 1 (\% wt calculated using formula).

\begin{tabular}{llllllll}
\hline RT & Peak & Area & Name of compound & \% Probability & Formula & MW & \% wt \\
\hline 3.96 & 281 & 2726166 & Cyclotetrasiloxane,octamethyl- & 96.3 & $\mathrm{C}_{8} \mathrm{H}_{24} \mathrm{O}_{4} \mathrm{Si}_{4}$ & 296 & 63.17 \\
4.63 & 115 & 214394 & Butandioic acid, dimethyl ester & 93.0 & $\mathrm{C}_{6} \mathrm{H}_{10} \mathrm{O}_{4}$ & 146 & 4.96 \\
6.62 & 355 & 982003 & Cyclopentasiloxane, decamethyl- & 95.5 & $\mathrm{C}_{10} \mathrm{H}_{30} \mathrm{O}_{5} \mathrm{Si}_{5}$ & 370 & 22.75 \\
9.66 & 341 & 275219 & Cyclohexasiloxane, dodecamethyl- & 98.1 & $\mathrm{C}_{12} \mathrm{H}_{36} \mathrm{O}_{6} \mathrm{Si}_{6}$ & 444 & 6.377 \\
18.78 & 74 & 117756 & Hexadecanoic acid, methyl ester & 71.4 & $\mathrm{C}_{17} \mathrm{H}_{34} \mathrm{O}_{2}$ & 270 & 2.72 \\
\hline
\end{tabular}

The isolate PDA 1 was identified to be Enterobacter asburiae by VITEK system.

Table 7. GC-MS analysis of isolate PDA 4.

\begin{tabular}{|c|c|c|c|c|c|c|c|}
\hline RT & Peak & Area & Name of compound & \% Probability & Formula & MW & $\% \mathrm{wt}$ \\
\hline 3.94 & 281 & 2215693 & Cyclotetrasiloxane, octamethyl- & 96.2 & $\mathrm{C}_{8} \mathrm{H}_{24} \mathrm{O}_{4} \mathrm{Si}_{4}$ & 296 & 75.4 \\
\hline 4.84 & 207 & 108392 & $\begin{array}{l}\text { Silicic acid, diethyl bis } \\
\text { (trimethylsilyl) ester }\end{array}$ & 29.5 & $\mathrm{C}_{10} \mathrm{H}_{28} \mathrm{O}_{4} \mathrm{Si}_{3}$ & 296 & 3.68 \\
\hline 5.25 & 297 & 91470 & $\begin{array}{l}\text { Benzoic acid, 2,4-bis } \\
\text { (trimethylsiloxy); methyl ester }\end{array}$ & 43.3 & $\mathrm{C}_{14} \mathrm{H}_{24} \mathrm{O}_{4} \mathrm{Si}_{2}$ & 312 & 3.11 \\
\hline 6.61 & 73 & 415231 & Cyclopentasiloxane, decamethyl- & 95.2 & $\mathrm{C}_{10} \mathrm{H}_{30} \mathrm{O}_{5} \mathrm{Si}_{5}$ & 370 & 14.13 \\
\hline 9.66 & 341 & 107528 & - & - & - & - & \\
\hline
\end{tabular}

The cetane number and CFPP values for isolate PDA1 are calculated according to formula mentioned. The results obtained after tabulation are mentioned in Table 5. With the help of these formulae the approximate values of cetane number and CFPP can be predicted. Cetane number of the isolate PDA 1 was calculated to be
61.39 approx which is more than the minimum value of Cetane number mentioned in literature.

High cetane numbers help ensure good cold start properties and minimize the formation of white smoke. It is well known that biodiesel cetane number depends on 
the feedstock used for its production. The longer the fatty acid carbon chains and the more saturated the molecules, the higher the cetane number. It is clear that the cetane number fits linearly with the degree of unsaturation. The cetane number for biodiesel should be a minimum of 51 (Ramos et al., 2009). CFPP value of biofuel of isolate PDA 1 is calculated to be -12.48 approx. Cold filter plugging point (CFPP) is an estimation of the lowest temperature prior to the formation of waxy solids that settle and plug filters and fuel lines. Acceptable values vary according to country climate and season (Bonturi et al., 2015). Distillate fuels typically develop operability problems such as wax settling and plugging of filters and fuel lines when overnight temperatures approach -10 and $-15^{\circ} \mathrm{C}$ (Ramos et al., 2009).

Enterobacter spp. are found to be capable of producing over 58.6\% - 80\% FAE and capable of processing over $12.4 \%$ of the TG in the reaction mixture (conversion of TG into DG plus FAE) (Escobar-Niño et al., 2014).

\section{Conclusion}

SCOs are lipids produced by oleaginous microorganisms including bacteria, yeast, fungi, and algae that are capable of accumulating at least $20 \%$ of their dry cell mass as lipids. Glucose can be converted by almost every microorganism. Therefore, it is suitable for screening experiments. Agro-industrial waste could be used as substrate to cultivate oleaginous microorganisms. A number of microorganisms belonging to the genera of algae, bacteria, yeast and fungi have the ability to accumulate lipids under specific cultivation conditions. Among them, utilization of oleaginous yeast is advantageous due to fast growth rate and high oil content compared to algae. To reduce the cost of microbial oils, the need for exploring cheap carbon sources such as glycerol instead of glucose is of paramount significance for industrial biodiesel production. Industrial waste being rich in simple sugars, serves as a growth medium which can be effectively utilised by wide variety of micro- organisms. Utilisation of crude glycerol for yeast oil production, which is a by product of biodiesel industry could be an interesting and promising area of research.

The effect of media composition, cultivation conditions such as $\mathrm{C} / \mathrm{N}$ ratio, nitrogen resources, temperature, $\mathrm{pH}$, oxygen, concentration of trace elements and inorganic salt on growth, and influence on lipid accumulation of microorganisms can be investigated. This can be studied by using different carbon sources and estimating the lipid conversion in comparison with substrate consumed. Exploration of new sources for isolation of potential lipid producing strains should be focussed. Genetic modification of these microorganisms can help to improve their performance for producing oils.

\section{Conflict of interest statement}

Authors declare that they have no conflict of interest.

\section{References}

Amaretti, A., Raimondi, S., Leonardi, A., Rossi, M., 2012. Candida freyschussii: An oleaginous yeast producing lipids from glycerol. Chem. Engg. Trans. 27, 139-144.

Bonturi, N., Matsakas, L., Nilsson, R., Christakopoulos, P., Miranda, E.A., Berglund, K. A., Rova, U., 2015. Single cell oil producing yeasts Lipomyces starkeyi and Rhodosporidium toruloides: Selection of extraction strategies and biodiesel property prediction. Energies. 8, 5040-5052.

Braunwald, T., Schwemmlein, L., Graeff-Honninger, S., French, W. T., Hernandez, R., Holmes, W. E., Claupein, W., 2013. Effect of different C/N-ratios on carotenoid and lipid production by Rhodotorula glutinis. Appl. Microbiol. Biotechnol. 97, 6581-6588.

Castanha, R. F., Salgado de Morais, L. A., Mariano, A. P., Rosim Monteiro, R. T., 2013. Comparison of two lipid extraction methods produced by yeast in cheese whey. Braz. Arch. Biol. Technol. 56(4), 629-636.

Escobar-Niño, A, Luna, C., Luna, D., Marcos, A.T., Cánovas, D., Mellado, E., 2014. Selection and characterization of biofuel-producing environmental bacteria isolated from vegetable oil-rich wastes. PLoS One. 9(8), e104063.

Gohel, H. R., Ghosh, S.K., Braganza, V.J., 2013. Yeast as a viable and prolonged feedstock for biodiesel production. Int. J. Renew. Energy Res. 3(1), 126-131.

Kraisintu, P., Yongmanitchai, W., Limtong, S., 2010. Selection and optimization for lipid production of a newly isolated oleaginous yeast, Rhodosporidium toruloides DMKU3-TK16. Kasetsart J. Nat. Sci. 44, 436-445.

Matsakas, L., Sterioti, A-.A., Rova, U., Christakopoulos, P., 2014. Use of dried sweet sorghum for the efficient production of lipids by the yeast Lipomyces starkeyi CBS 1807. Industr. Crops Prod. 62, 367-372.

Neema, P.M., Kumari, A., 2013. Isolation of lipid producing yeast and fungi from secondary sewage sludge and soil. Aust. J. Basic Appl. Sci. 7(9), 283-288.

Patel, R., Dadida, C., Sarker, K., Sen, D. J., 2015. Sudan dyes as lipid soluble aryl-azo naphthols for microbial staining. Eur. J. Pharmaceut. Med. Res. 2(3), 417-425.

Ramos, M. J., Fernandez, C. M., Casas, A., Rodriguez, L., Perez, A., 2009. Influence of fatty acid composition of raw materials on biodiesel properties. Bioresour. Technol. 100, 261-268. 
Ruan, Z., Zanotti, M., Wang, X., Ducey, C., Liu, Y., 2012. Evaluation of lipid accumulation from lignocellulosic sugars by Mortierella isabellina for biodiesel production. Bioresour. Technol. 110, 198-205.

Saravanan, S., Chandrashekhar, S., 2013. Predictive equations for viscosity and cetane number of biodiesel. German J.
Renew. Sustain. Energy Res. 1(1), 23-28.

Schulze, I., Hansen, S., Grobhans, S., Rudszuck, T., Ochsenreither, K., Syldatk, C., Neumann, A., 2014. Characterization of newly isolated oleaginous yeasts Cryptococcus padzolicus, Trichosporon porosum and Pichia segobiensis. AMB Express. 18(4), 24.

\section{How to cite this article:}

Mane, S., Raut. S. V., 2016. Isolation of lipid producing organisms and their properties as biofuel. Int. J. Curr. Res. Biosci. Plant Biol. 3(8), 81-87. doi: http://dx.doi.org/10.20546/ijcrbp.2016.308.013 